\title{
The Maternal Emotional Climate Predicts Twin Sibling Relationship Quality
}

\author{
Katharine M. Mark, Alison Pike, Rachel M. Latham, and Bonamy R. Oliver \\ School of Psychology, University of Sussex, Brighton, England
}

\begin{abstract}
We investigated the association between maternal expressed emotion and twin relationship quality, after controlling for a maternal questionnaire measure of the mother-child relationship. This was explored within a community sample of 156 mothers and their two young twin children $\left(M_{\text {child age }}=3.69\right.$ years; $S D_{\text {child age }}=0.37$ ). Mothers reported on the twin-twin relationship and the mother-child relationship via questionnaire. They were also interviewed about each child using the innovative Preschool Five Minute Speech Sample (Daley et al., 2003), which yields information about relative positive:negative maternal expressed emotion. Mothers who expressed more family-wide positive emotion and less family-wide negative emotion also reported more positivity, but not negativity, within the twin relationship - even when controlling for questionnaire reports of the mother-child relationship. Counter to expectations, discrepancies in mothers' expressed emotion between their twins also predicted more positive sibling relationships. Our findings corroborate the well established spill-over effect, whereby families are viewed as emotional units of interdependent individuals, none of whom can be understood in isolation from one another. Most importantly, the Preschool Five Minute Speech Sample provides information about mothering that questionnaire reports may not, and thus it is a useful tool in better understanding the twin family system.
\end{abstract}

Keywords: five-minute speech sample, maternal expressed emotion, parental differential treatment, sibling relationship quality, spill-over, twins

This research is situated within a family systems approach, whereby families are viewed as emotional units of interdependent individuals, none of whom can be understood in isolation from one another (Bowen, 1978). It is now well documented that the nature and valence of parenting can 'spill over' into other familial relationships, including the sibling bond (Pike et al., 2005). The majority of past studies have recruited non-twin siblings and employed questionnaires or observations to access such family dynamics. Capturing an additional, more nuanced perspective of the emotional climate of the family may be key to enhancing our understanding. For the first time, the current study investigated the prediction of twin relationship quality from an interview measure of maternal expressed emotion, the Preschool Five Minute Speech Sample (Daley et al., 2003). We controlled for a questionnaire measure of the mother-child relationship, and participants were a community sample of mothers and their twin children. Prior to describing previous research linking the mother-child and sibling and twin subsystems, we provide an overview of the Preschool Five Minute Speech Sample (Daley et al., 2003).

\section{The Preschool Five Minute Speech Sample}

The Five Minute Speech Sample was originally developed by Magana et al. (1986) as a quick and reliable way to measure levels of expressed emotion within families. Expressed emotion is a construct that allows researchers to quantify the feelings individuals convey about family members, by focusing on critical and hostile attitudes, and extreme emotional involvement from parents toward their adult children (Brown \& Rutter, 1966). These specific intrafamilial traits have repeatedly been associated with relapse in those suffering from schizophrenia (Leff \& Vaughn, 1981) and, more recently, have emerged in relation to psychopathology in middle childhood (Baker et al., 2000). In 2003, Daley and colleagues modified the Five Minute Speech Sample (Magana et al.) for use with parents of preschool-aged children.

\section{RECEIVED 22 September 2016; ACCEPTED 24 January 2017}

ADDRESS FOR CORRESPONDENCE: Bonamy Oliver, School of Psychology, University of Sussex, Brighton, East Sussex, BN1 9QH, England. E-mail: Bonamy.Oliver@sussex.ac.uk 
This latter version, the Preschool Five Minute Speech Sample (Daley et al., 2003), was used in the current study, and includes coding of positive, as well as negative, expressions of emotion.

The unusual interview-style structure of the Five Minute Speech Sample (Magana et al., 1986) and the Preschool Five Minute Speech Sample (Daley et al., 2003) requires parents to deliver a five-minute monologue about their child. Such a procedure is thought to encourage the disclosure of authentic and unbiased feelings from mothers and fathers. Thus, the measure is able to overcome some of the limitations associated with self-report questionnaires and researcherled observations. In this way, it may help to improve our understanding of family dynamics. Specifically, questionnaire methods are often criticized because of the risk of rater bias - parents may be more likely to present themselves in a positive light, and to report being more consistent in their behavior and feelings toward each of their children than is actually the case (Kowal et al., 2006). Observational coding of parenting, often based on a parent and child carrying out a shared task, is commonly considered to be the 'gold standard'. However, these tasks require the willingness of both parents and children to participate, in a staged, and often artificial, environment (Yelland \& Daley, 2009). Moreover, we would argue that researchers may not capture a typical period of interaction, since they only tend to observe parent-child pairs for five to ten minutes on one particular day (Pike \& Oliver, 2015).

The Five Minute Speech Sample (Magana et al., 1986) and Preschool Five Minute Speech Sample (Daley et al., 2003) provide a valuable complement to more traditional measures, because parents' spontaneous speech: (1) is less likely to be affected by rater bias than are structured questionnaire responses; (2) is, unlike observational interactions, unobtrusive, as it can be carried out via telephone interview; and (3) has been shown to be reflective of how parents behave toward their children on a daily basis (Wamboldt et al., 2000).

\section{Parenting and Sibling Relationship Quality}

Consideration of multiple relationships within the family, and recognizing that dyadic subsystems of relationships influence one another, is at the heart of the family systems approach (Bowen, 1978). Specifically, the current study is informed by the well established spill-over hypothesis (Engfer, 1988), which argues for the transfer of positive and negative emotion from one familial bond to another. Such transmission has been displayed across varying interactions within a family unit (e.g., between the marital and the parent-child relationship; Erel \& Burman, 1995), but it is the spill-over between mother-child and sibling pairings that is of interest here. Empirical evidence supports this effect - research has found that problematic mother-child relations go hand in hand with more hostile sibling relations (Brody et al., 1994), and that positive mother-child relations are associated with more intimate sibling relations (Brody, 1998). Indeed, Pike and colleagues (2005) suggest that parental feelings and behaviors may be directly modeled by children in their interactions with siblings.

\section{Differential Parenting and Sibling Relationship Quality}

Both absolute levels of parenting within families, and the differential expression of parents' positivity and negativity toward siblings within families, have been shown to predict sibling relationship quality (Shanahan et al., 2008). From an early age, children are intensely aware of - and compare - the behavior of their parents toward them versus their sibling(s) (Dunn \& Munn, 1985), and parental differential treatment has been associated with more conflictual sibling relationships (McHale et al., 1995). However, despite the negative consequences that this unequal treatment can have on both sibling relationship quality and on individual children's outcomes (Jenkins et al., 2012), it is fairly commonplace within families (Brody et al., 1998). Interestingly, Kowal and Kramer (1997) found that the usual negative effects of parents' differential behavior on sibling relationship quality were ameliorated if children perceived such conduct to be fair and justified in the circumstances.

\section{Expressed Emotion and Sibling Relationship Quality}

Although maternal expressed emotion is known to influence the atmosphere within the home environment (McCarthy et al., 2004), there has been little research investigating the connection between the Five Minute Speech Sample (Magana et al., 1986) or the Preschool Five Minute Speech Sample (Daley et al., 2003) and sibling relationship quality. The interview measures have been included in sibling-based research, to the extent that parents have completed speech samples for two children within the same family. For example, Cartwright and colleagues (2011) carried out the Five Minute Speech Sample (Magana et al., 1986) with parents of non-twin siblings (one who had been diagnosed with Attention Deficit Hyperactivity Disorder and one who had not), and found that 'maternal expressed emotion is an important marker of parental response to Attention Deficit Hyperactivity Disorder' (p. 10). The authors confirmed that the parent-driven emotional climate was predominantly a child effect, with little or no role for shared family influences in the components of the Five Minute Speech Sample (Magana et al., 1986). Despite such research, however, and as far as we are aware, Petalas and colleagues (2012) authored the only study looking directly at the association between maternal expressed emotion and the sibling bond within a clinical sample of 5- to 17-yearold children with Attention Deficit Hyperactivity Disorder. Here, more conflict was reported between siblings when mothers made many critical comments about either one or both children. 


\section{Twin Relationship Quality}

Twins represent an unusual sibling dyad, but the Office for National Statistics (2013) suggests that twin births are becoming increasingly common -15.6 out of every 1,000 deliveries were multiple births in the year 2013. Both classic literature and the modern media tend to portray the twinship bond as one that is exceptionally special and intimate (Playfair, 2002). Indeed, this view has been supported by a number of empirical studies, claiming that twin dyads are unique due to the lack of birth order and developmental differences between them (Burlington, 1945; Fraley \& Tancredy, 2012; Segal, 1999).

In the context of parenting, it is known that mothers of twins tend to be less responsive to, to have less physical contact with, and to talk less to their children in comparison to mothers of non-twins (Leonard \& Denton, 2006). Parents of twins often encounter childrearing challenges, simultaneously trying to treat each child fairly and equally while responding to their differences and preferences, which can lead to considerable internal conflict, guilt, and feelings of inadequacy (Beck, 2002). Parenting experiences of families raising twin children may provide nuanced insights, due to the unusual and somewhat more stressful nature of mothering and fathering in this situation. Studying twinships may be particularly helpful when considering parental differential treatment. Parenting that is perceived as being unequal or unfair to children may be felt more keenly by twins in comparison to non-twins. Differences in developmental stages, and therefore needs, are the primary reason why siblings may accept discrepancies in the caregiving provided by their parents (Kowal et al., 2006). However, recruiting twins controls for any age and age gap variance, thus removing a major determining factor of parenting, and particularly differential treatment (O'Connor \& Croft, 2001). Ultimately, studying a twin sample eradicates these central confounding factors from the sibling dyad and allows us to put parenting, and especially differential parenting, under the microscope.

When thinking specifically about maternal expressed emotion toward twins, the pool of research available is virtually non-existent. Caspi and colleagues (2004) carried out the Five Minute Speech Sample (Magana et al., 1986) with mothers of twins, and found that their differential emotional attitudes toward their children were associated with subsequent antisocial behavior at age 7 . The authors ruled out the possibility that the link was genetically mediated and instead concluded that maternal expressed emotion is an environmentally mediated risk factor for problematic child behavior. However, as far as we are aware, no studies have investigated the prediction of twin relationship quality from mothers' emotional attitudes toward their children.

\section{The Current Study}

For the first time, the present study used the Preschool Five Minute Speech Sample (Daley et al., 2003) to investigate spill-over between maternal expressed emotion and twin relationship quality, in order to better conceptualize the relationships between these family dyads. Importantly, this link was explored while accounting for maternal questionnaire reports of the mother-child relationship. To address the lack of research focusing on twin relationship quality, we recruited a community sample of mothers with young twin children (aged 3.69 years). We also included both family-wide levels of maternal expressed emotion, as well as a simple differences model (Dunn et al., 1990) of differential expressed emotion between siblings within a family, as predictors of twin relationship quality.

Specifically, we hypothesized that: (a) mothers would show different patterns of expressed emotion toward each of their twins; (b) family-wide maternal expressed emotion (i.e., mothers' average expressed emotion across both twins) would predict twin relationship quality, after controlling for questionnaire reports of the mother-child relationship specifically, positive family-wide maternal expressed emotion would predict more positive, and less negative, twin relationship quality, and negative family-wide maternal expressed emotion would predict more negative, and less positive, twin relationship quality; and (c) differential maternal expressed emotion (i.e., the difference between mothers' expressed emotion toward one twin compared to the other) would predict more negative, and less positive, twin relationship quality, after controlling for questionnaire reports of the mother-child relationship.

\section{Method}

\section{Participants and Recruitment}

Data were collected from mothers, along with their twin children, as part of the Twins, Family and Behavior (TFaB) longitudinal study. Mothers of twins born within England and Wales in 2009 were contacted by the Office for National Statistics and asked if they would like to participate in the study. Following this, we expanded our sample by: (a) broadening the participation criteria to include twins born in 2010, as well as in 2009; (b) asking participants to put us in touch with any other eligible families they knew who might like to take part; and (c) advertising in a well-known registered twins charity, the Twins and Multiple Births Association (TAMBA), newsletter. Eight hundred mothers were approached by the Office for National Statistics, and 287 (35.9\%) agreed to take part by returning a form detailing their contact information. A further 59 families came forward to participate following our additional recruitment attempts; thus, 346 families were recruited overall. Of these 346 mothers, 284 returned their initial postal questionnaire.

Data were collected in four phases, over a 2- to 3-year period. The current article focuses on 156 of these mothers of twins. This subset of participants had completed an initial postal questionnaire, a telephone interview, and a 
follow-up postal questionnaire, during the first, second, and fourth phases of the study, respectively. At phase 1, 89.0\% of the participating families were intact two-parent households where the biological mother and father were either married or cohabiting, while $9.7 \%$ of mothers reported being single (either unmarried, separated, divorced, or widowed), and $1.3 \%$ stated they were either married or cohabiting with someone other than the twins' biological father. Mothers had an average age of 37.99 years $(S D=4.26)$. Children had an average age of 3.69 years $(S D=0.37)$ at phase $1,4.67$ years $(S D=0.39)$ at phase 2 , and 5.98 years $(S D=0.49)$ at phase 4 .

Twin zygosity was determined using a parental questionnaire, shown to be more than $95 \%$ accurate when compared to blood (Plomin et al., 1991) and DNA (Price et al., 2000) testing procedures. Of the 156 twin pairs included in the study, four pairs could not be classified in terms of their zygosity. Of the remaining 152 pairs, 59 (38.8\%) were monozygotic (or identical), 44 (28.9\%) were dizygotic (or fraternal) same-sex, and $49(32.2 \%)$ were dizygotic opposite-sex.

In comparison with the national average for England and Wales (Office for National Statistics, 2014), the sample was skewed toward those of higher socio-economic status. The mothers included were substantially more qualified $69.5 \%$ of the sample reported having an undergraduate degree or above as their highest educational attainment, compared to $27.2 \%$ of the general population. Correspondingly, only $0.6 \%$ of our participants reported having no educational qualifications, compared to $22.7 \%$ of the general population.

\section{Procedure and Measures}

Participants completed an initial postal questionnaire at phase 1 of the study, as well as a follow-up postal questionnaire at phase 4 . Researchers also carried out 40 -minute semi-structured telephone interviews with each mother at phase 2.

The mother-child relationship. For the Parent-Child Relationship Scale questionnaire (Hetherington \& Clingempeel, 1992), administered during phase 1 of the TFaB study via postal questionnaire, mothers were asked to rate 15 items about aspects of their relationship with each of their twins. These were rated on a 5-point scale, ranging from $1=$ not at all to $5=$ extremely. Two subscales are derived from this measure: (1) mother-child relationship positivity; for example, 'How affectionate is your child toward you?' (Cronbach's alphas $=0.75$ and 0.69 for maternal reports concerning the older and younger twins, respectively); and (2) mother-child relationship negativity; for example, 'How much do you criticise your child?' (Cronbach's alphas = 0.70 and 0.72 for maternal reports concerning the older and younger twins, respectively).
Expressed emotion. The Preschool Five Minute Speech Sample (Daley et al., 2003) was used to assess maternal expressed emotion, in relation to each twin separately, during a telephone interview at phase 2 of the study. Specifically, a researcher told each mother: 'I'd like to hear your thoughts and feelings about [twin name], in your own words and without me interrupting with any questions or comments. When I ask you to begin, I would like you to speak for 5 minutes, telling me what kind of a person [twin name] is and how the two of you get along together. During this time I prefer not to answer any questions or comments, but I will tell you when the five minutes have passed.' If the participant stopped speaking before the 5 minutes had elapsed, we waited 30 seconds before prompting, as respondents often continued talking on their own. After 30 seconds had passed, the respondent was prompted with the comment: 'Please tell me anything about [twin name] for a few more minutes.' If the respondent still did not speak, we simply allowed the full 5 minutes to elapse before moving on to the next part of the interview.

The Preschool Five Minute Speech Sample (Daley et al., 2003) was coded in pairs by trained researchers, using an adapted version of the original coding scheme. There were two frequency counts for coding: (1) positive comments, which are usually descriptive words or statements that reflect praise, approval, or appreciation toward the child, or that indicate a positive trait (e.g., '[Twin name] is sociable'); and (2) critical comments, which are usually descriptive words or statements that find fault with the child, or that indicate a negative trait (e.g., '[Twin name] is irritable'). For each minute of the Preschool Five Minute Speech Sample (Daley et al., 2003), pairs of coders tallied how many times each mother made one of these statements. Initially, we carried out this coding individually, without conferring with our coding partner, and subsequently, after each minute of speech, coders came together to discuss the scores they had assigned. When disagreements arose, coders deliberated over the score until an agreement was reached. Interrater reliability for the initial individual codes was 0.90 for positive comments and 0.83 for critical comments.

Proportion scores were computed, reflecting the number of positive comments compared to the number of critical comments made by mothers toward each twin. The former were divided by the latter, so that values between 0 and 1 were indicative of more critical than positive comments, and values above 1 were indicative of more positive than critical comments. For example, in a particular family, if a mother uttered 3 positive comments and 1 critical comment about one of her twins, this would generate a proportion score of $3(3 \div 1=3)$; whereas if a mother uttered 1 positive comment and 3 critical comments, this would generate a proportion score of $0.33(1 \div 3=0.33)$.

Twin relationship quality. Twin relationship quality was measured using an adapted version of the Maternal 
Interview of Sibling Relationships (Stocker et al., 1989). At phase 4 of the study, mothers were asked to rate how often their children displayed 13 varying behaviors relating to different aspects of the sibling relationship, including companionship, quarrels, sharing, competing, and jealousy, via a follow-up postal questionnaire. Four of the items were scored for the twin sibling relationship overall (e.g., 'Of the time the siblings spend together, how often do they play together?'), and 9 required ratings for the older twin and the younger twin individually (e.g., 'On a day-to-day basis, how often does [older twin name] show affection toward [younger twin name]?; and how often does [younger twin name] show affection toward [older twin name]?'). Varying response scales were used throughout; the most common were a percentage-based scale, where $1=$ less than $5 \%$ of their time together and $6=$ almost all of their time together, and a frequency-based scale, where $1=$ once a month or less and $6=$ just about every day. Factor analysis yielded composite scores for twin relationship quality positivity (11 items) and twin relationship quality negativity (3 items). Resultant Cronbach's alphas for these scales were 0.85 for the former and 0.78 for the latter.

\section{Results}

\section{Preliminary Analyses}

First, unstandardized residual variables were created for mother reports of twin relationship quality positivity and negativity at phase 4 , in order to control for both the number of boys within each twin pair and the children's ages. These residual scores were used for all analyses, apart from for the descriptive statistics.

Additionally, overall family-wide ratings and difference scores between twins were created for both the ParentChild Relationship Scale (Hetherington \& Clingempeel, 1992) and for the Preschool Five Minute Speech Sample (Daley et al., 2003) proportion measures. In order to create the overall family-wide indicators, we calculated family averages (across the two twins), and to create the differential indicators, difference scores were calculated. For example, in a particular family a mother might score a 2 for mother-child relationship positivity on the ParentChild Relationship Scale (Hetherington \& Clingempeel, 1992) in relation to the older twin, and a 3 on the same measure for the younger twin. Family-wide mother-child positivity would then be $2.5([3+2] \div 2=2.5)$. The associated difference scores were calculated by taking the absolute difference between the twins' scores. Here, differential mother-child positivity would be $1(3-2=1)$. It is worth noting that we did not assess the direction of differential scores for the Parent-Child Relationship Scale (Hetherington \& Clingempeel, 1992) or the Preschool Five Minute Speech Sample (Daley et al., 2003). In other words, we did not attend to whether it was the older twin or the younger twin that received a higher score on these

\section{TABLE 1}

Descriptive Statistics for All Study Variables

\begin{tabular}{lrccc}
\hline & $M$ & $S D$ & Range & t value \\
\hline Phase 1 - PCRS questionnaire & & & & \\
Family-wide M-C positivity & 3.26 & 0.35 & $2.25-3.90$ & - \\
Family-wide M-C negativity & 1.29 & 0.60 & $0.00-3.50$ & - \\
Differential M-C positivity & 0.09 & 0.16 & $0.00-0.90$ & $7.12^{* * *}$ \\
$\quad$ Differential M-C negativity & 0.21 & 0.27 & $0.00-1.00$ & $9.66^{* * *}$ \\
Phase 2 - PFMSS telephone interview & & & \\
$\quad$ Family-wide maternal EE & 3.67 & 2.70 & $0.50-14.00$ & - \\
$\quad$ Differential maternal EE & 3.03 & 3.23 & $0.00-14.80$ & $9.95^{* * *}$ \\
Phase 4 - MISR questionnaire & & & & \\
$\quad$ TRQ positivity & 3.77 & 0.61 & $1.30-5.89$ & - \\
TRQ negativity & 2.45 & 1.08 & $0.00-5.00$ & - \\
\hline
\end{tabular}

Note: PCRS $=$ Parent-Child Relationship Scale; PFMSS $=$ Preschool Five Minute Speech Sample; MISR = Maternal Interview of Sibling Relationships; $\mathrm{M}-\mathrm{C}=$ mother-child; $\mathrm{EE}=$ expressed emotion; $\mathrm{TRQ}=$ twin relationship quality. $t$ values are from one-sample $t$ tests, where the mean value of each variable was compared to a value of zero. $* * * p<.001$.

particular measures because, in either case, more differential maternal reports were expected to relate to poorer twin relationship quality. Thus, these absolute differences reflect the magnitude, but not the direction, of any discrepancies described by mothers.

\section{Descriptive Statistics}

Descriptive statistics for all study variables are shown in Table 1. In order to assess whether the mean values of the differential mother-child relationship and the expressed emotion variables differed from a null value of zero, onesample $t$ tests were conducted. All measures tested had mean values that were significantly greater than zero. This indicated that mothers within our sample generally did make a significant amount of positive and critical comments about their children during the Preschool Five Minute Speech Sample (Daley et al., 2003), and also tended to display differential feelings and emotions when talking about each of their twins.

\section{Correlations}

Table 2 shows correlations among the mother-child relationship variables, the expressed emotion variables, and the residualized twin relationship quality variables. Five out of a possible 12 correlations were significant, all but one of which were in the expected direction. For the family-wide mother-child relationship scores from the questionnaire, mothers who reported a more positive relationship with both children also reported more positivity within the twin relationship. Similarly, mothers who reported a more negative relationship with both children also reported more negativity between the twin siblings. In terms of the differential mother-child relationship scores from the questionnaire, mothers who reported having a more positive relationship with one twin compared to the other also reported less positivity within the twin relationship. For the proportional expressed emotion variables, mothers 
TABLE 2

Correlations Among the MISR, the PCRS, and the PFMSS Measures

\begin{tabular}{lll}
\hline & \multicolumn{2}{c}{ Phase 4 - MISR questionnaire } \\
\cline { 2 - 3 } & TRQ positivity & TRQ negativity \\
\hline Phase 1 - PCRS questionnaire & & \\
Family-wide M-C positivity & $0.28^{* * *}$ & -0.02 \\
Family-wide M-C negativity & -0.06 & $0.22^{* *}$ \\
Differential M-C positivity & $-0.18^{*}$ & -0.07 \\
Differential M-C negativity & -0.08 & 0.04 \\
Phase 2 - PFMSS telephone interview & \\
Family-wide maternal EE & $0.17^{*}$ & 0.04 \\
Differential maternal EE & $0.27^{* *}$ & 0.03
\end{tabular}

Note: MISR = Maternal Interview of Sibling Relationships; PCRS = ParentChild Relationship Scale; PFMSS = Preschool Five Minute Speech Sample; $T R Q=$ twin relationship quality; $M-C=$ mother-child; $\mathrm{EE}=$ expressed emotion. We used unstandardized residuals of TRO positivity and TRQ negativity here, in order to account for the age and gender of twins.

${ }^{*} p<.05 ;{ }^{* *} p<.01 ;{ }^{* * *} p<.001$

who made more family-wide positive than family-wide critical expressed emotion comments also reported more positivity between the twin siblings. Unexpectedly, mothers who were more differential in terms of their expressed emotion tended to report more positivity between the twin siblings.

\section{Regression Analyses}

In order to assess whether the maternal expressed emotion measures predicted twin relationship quality over and above the mother-child questionnaire scores, we carried out hierarchical multiple regressions for twin relationship quality positivity and twin relationship quality negatively separately. These are shown in Table 3 and Table 4 . The family-wide mother-child relationship measures (familywide mother-child positivity and family-wide motherchild negativity) from the questionnaire at phase 1 were entered in step 1; family-wide maternal expressed emotion was entered in step 2; the differential mother-child relationship measures (differential mother-child positivity and differential mother-child negativity) from the questionnaire were entered in step 3; and differential maternal expressed emotion was entered in step 4 . By entering the variables in this order, we were able to test whether maternal expressed emotion could predict twin relationship quality, while controlling for the mother-child relationship.

Twin relationship quality positivity. Table 3 shows the regression analysis for twin relationship quality positivity. Family-wide mother-child positivity was a significant predictor of twin relationship quality positivity in all 4 steps. More family-wide mother-child positivity, from the questionnaire reports, was predictive of more twin sibling positivity. In step 2 and step 3 , and in line with our expectations, family-wide maternal expressed emotion also significantly predicted twin relationship quality positivity, over and above the questionnaire measure of the

\section{TABLE 3}

The PCRS and the PFMSS Measures, Regressed onto TRO Positivity

\begin{tabular}{lrcc}
\hline & $b$ & $S E b$ & $\beta$ \\
\hline Step 1 - PCRS questionnaire & & & \\
Constant & -1.46 & 0.47 & \\
Family-wide M-C positivity & 0.45 & 0.14 & $0.30^{* *}$ \\
Family-wide M-C negativity & -0.02 & 0.09 & -0.02 \\
Step 2 - PFMSS telephone interview & & & \\
Constant & -1.62 & 0.46 & \\
Family-wide M-C positivity & 0.44 & 0.13 & $0.30^{* *}$ \\
Family-wide M-C negativity & -0.03 & 0.09 & -0.04 \\
Family-wide maternal EE & 0.05 & 0.02 & $0.22^{* *}$ \\
Step 3 - PCRS questionnaire & & & \\
Constant & -1.47 & 0.50 & \\
Family-wide M-C positivity & 0.40 & 0.15 & $0.27^{* * *}$ \\
Family-wide M-C negativity & -0.03 & 0.09 & -0.03 \\
Family-wide maternal EE & 0.05 & 0.02 & $0.22^{* *}$ \\
Differential M-C positivity & -0.23 & 0.31 & -0.08 \\
Differential M-C negativity & 0.00 & 0.19 & 0.00 \\
Step 4 - PFMSS telephone interview & & & \\
Constant & -1.31 & 0.51 & \\
Family-wide M-C positivity & 0.37 & 0.15 & $0.24^{* *}$ \\
Family-wide M-C negativity & -0.03 & 0.09 & -0.03 \\
Family-wide maternal EE & 0.01 & 0.04 & 0.04 \\
Differential M-C positivity & -0.31 & 0.31 & -0.10 \\
Differential M-C negativity & -0.02 & 0.18 & -0.01 \\
Differential maternal EE & 0.04 & 0.03 & $0.23^{\dagger}$ \\
\hline
\end{tabular}

Note: $R^{2}=0.09$ for step $1 ; \Delta R^{2}=0.05$ for step $2(p=.01) ; \Delta R^{2}=0.01$ for step $3(p=.75) ; \Delta R^{2}=0.02$ for step $4(p=.13)$. PCRS $=$ Parent-Child Relationship Scale; PFMSS = Preschool Five Minute Speech Sample; $\mathrm{TRQ}=$ twin relationship quality; $\mathrm{M}-\mathrm{C}=$ mother-child; $\mathrm{EE}=$ expressed emotion. We used unstandardized residuals of TRQ positivity here, in order to account for the age and gender of twins. $\dagger p<.10$ (trend level); ${ }^{* *} p<.01 ;{ }^{* * *} p<.001$.

mother-child relationship. The more positivity (vs. negativity) in mothers' expressed emotion, the more positivity reported in the twin-sibling relationship. Finally, and unexpectedly (though reflective of the correlations), step 4 showed that more differential maternal expressed emotion also predicted (at trend level) positivity between the twin siblings.

Twin relationship quality negativity. Table 4 shows the regression analysis for of twin relationship quality negativity. Family-wide mother-child positivity, from the questionnaire reports, was a (trend level) predictor of twin relationship quality negativity in step 1 and step 2 . More familywide mother-child positivity was predictive of less twin sibling negativity. In step 3 and step 4, however, when all other variables were taken into account, questionnaire reports of family-wide mother-child negativity became positively predictive (at trend level) of negativity between twin siblings, and family-wide mother-child positivity was no longer significant.

\section{Discussion}

The link between parenting and the sibling bond has long been established (Brody, 1998; Dunn \& Munn, 1985). However, for the first time, we investigated the spill-over 


\section{TABLE 4}

The PCRS and the PFMSS Measures, Regressed onto TRQ Negativity

\begin{tabular}{|c|c|c|c|}
\hline & $b$ & SE $b$ & $\beta$ \\
\hline \multicolumn{4}{|l|}{ Step 1 - PCRS questionnaire } \\
\hline Constant & -1.38 & 0.88 & \\
\hline Family-wide M-C positivity & 0.36 & 0.26 & $0.13^{\dagger}$ \\
\hline Family-wide $\mathrm{M}-\mathrm{C}$ negativity & 0.21 & 0.17 & 0.12 \\
\hline \multicolumn{4}{|c|}{ Step 2 - PFMSS telephone interview } \\
\hline Constant & -1.37 & 0.89 & \\
\hline Family-wide M-C positivity & 0.36 & 0.26 & $0.13^{\dagger}$ \\
\hline Family-wide $\mathrm{M}-\mathrm{C}$ negativity & 0.21 & 0.17 & 0.12 \\
\hline Family-wide maternal EE & -0.00 & 0.04 & -0.01 \\
\hline \multicolumn{4}{|l|}{ Step 3 - PCRS questionnaire } \\
\hline Constant & -0.89 & 0.97 & \\
\hline Family-wide M-C positivity & 0.22 & 0.28 & 0.08 \\
\hline Family-wide $\mathrm{M}-\mathrm{C}$ negativity & 0.25 & 0.17 & $0.14^{\dagger}$ \\
\hline Family-wide maternal EE & -0.01 & 0.04 & -0.01 \\
\hline Differential M-C positivity & -0.69 & 0.60 & -0.12 \\
\hline Differential $\mathrm{M}-\mathrm{C}$ negativity & -0.13 & 0.36 & -0.04 \\
\hline \multicolumn{4}{|c|}{ Step 4 - PFMSS telephone interview } \\
\hline Constant & -0.77 & 0.99 & \\
\hline Family-wide M-C positivity & 0.20 & 0.29 & 0.07 \\
\hline Family-wide $\mathrm{M}-\mathrm{C}$ negativity & 0.25 & 0.17 & $0.14^{\dagger}$ \\
\hline Family-wide maternal EE & -0.04 & 0.07 & -0.08 \\
\hline Differential M-C positivity & -0.75 & 0.61 & -0.13 \\
\hline Differential M-C negativity & -0.15 & 0.36 & -0.04 \\
\hline Differential maternal EE & 0.03 & 0.05 & 0.09 \\
\hline \multicolumn{4}{|c|}{$\begin{aligned} \text { Note: } & R^{2}=0.03 \text { for step } 1 ; \Delta R^{2}=0.00 \text { for step } 2(p=.94) ; \Delta R^{2}=0.21 \text { for } \\
& \text { step } 3(p=.41) ; \Delta R^{2}=0.00 \text { for step } 4(p=.56) . P C R S=\text { Parent-Child } \\
& \text { Relationship Scale; PFMSS = Preschool Five Minute Speech Sample; } \\
& \text { TRQ = twin relationship quality; M-C = mother-child; EE = expressed } \\
& \text { emotion. We used unstandardized residuals of TRQ negativity here, in } \\
& \text { order to account for the age and gender of twins. } \\
& \dagger p<.10 \text { (trend level). }\end{aligned}$} \\
\hline
\end{tabular}

between maternal expressed emotion and twin relationship quality while accounting for a questionnaire measure of the mother-child relationship. This study was novel in that a specific, and under-researched, aspect of mothering was assessed using the innovative Preschool Five Minute Speech Sample (Daley et al., 2003). Furthermore, we explored our aims within a community sample of mothers and their two young twin children, in order to see whether the speech-based interview measure could help us better understand dynamics within families with twins. By creating both average and differential scores of mothers' expressed emotion, we were also able to examine whether mothering was stable across children, and whether it was the child-specific or family-wide aspects of parenting that were most salient for twin relationship quality.

In line with our first hypothesis (a), there was evidence that mothers within our sample showed different patterns of expressed emotion toward each of their twins. One sample $t$ tests revealed that they displayed significant levels of differential expressed emotion when talking about their children, and also when reporting on their relationship with their children via questionnaire. Our second hypothesis (b), that family-wide maternal expressed emotion would predict twin relationship quality over and above questionnaire reports of the mother-child relationship, was partially confirmed. Making proportionately more positive than critical expressed emotion comments when describing their children predicted mothers' reports of twin relationship quality positivity, but not negativity, after the mother-child relationship was controlled for. Unexpectedly, results concerning our third and final hypothesis (c), that differential maternal expressed emotion would predict twin relationship quality over and above questionnaire reports of the mother-child relationship, were in the unexpected direction. Making proportionately more positive than critical expressed emotion comments about one twin compared to the other predicted twin relationship quality positivity, but not negativity.

\section{Differential Expressed Emotion}

Supporting both our first hypothesis (a), and the relevant previous research (Brody et al., 1998; Shanahan et al., 2008), this study revealed some clear differences in the way mothers described each of their twins during the Preschool Five Minute Speech Sample (Daley et al., 2003). Indeed, this disparity in mothers' expression of feelings and behavior toward their twin siblings was frequent, and thus seems to be a relatively typical occurrence within everyday family life.

In general, parents tend not to differentiate between their children, and particularly their monozygotic twins, when using traditional self-report measures, and therefore, score siblings within a family very similarly to one another (Caspi et al., 2004; Pike et al., 1996). Consequently, the evidence of differential expressed emotion in this twin sample is a promising indication of the potential utility of the speechbased measure employed. We suggest that the way mothers freely describe their children may capture variance in parenting that is not revealed by typically employed questionnaire assessments; and, in this way, the Preschool Five Minute Speech Sample (Daley et al., 2003) is a valuable tool for gaining a more complete picture of twin family life.

Family-Wide Mothering and Twin Relationship Quality Engfer's (1988) well established spill-over proposal, that emotion or behavior can be transferred from one familial bond to another within the home environment, was reinforced by the current study, as was our second hypothesis (b). Specifically, we found evidence of strong positive spill-over between the mother-child and the twin sibling subsystems. As expected, the utterance of more family-wide positive than critical comments by mothers about both of their children predicted positivity within the twin relationship, and these findings held after controlling for mothers' questionnaire reports (although, notably, not after differential maternal expressed emotion had been taken into account). Correspondingly, we also found that the questionnaire reports of family-wide mother-child positivity (across both siblings) predicted a closer bond between twins. Weak prediction also emerged for twin sibling relationship quality negativity, from the questionnaire reports of both family-wide mother-child positivity and 
family-wide mother-child negativity. These results replicate the work of Brody and colleagues (1994; 1998), linking closer mother-child relations with more affectionate sibling interactions, and more negative mother-child relations with more conflictual sibling interactions, and highlight the importance of the general emotional atmosphere within the home environment.

Although we did not explore the processes through which such transference may occur, it seems likely that social learning theory (Bandura, 1977), whereby individuals can learn new patterns of behavior through reinforcement and observation of others, is at play here. Indeed, authors suggest that children can copy helpful and loving maternal behaviors and emotions (Whiteman et al., 2011), as well as negative family dynamics (Straus et al., 1980), and then apply this modeling to subsequent sibling interactions. In the context of this research, mothers' use of positive language predicted the nature of the twin relationship. Perhaps being exposed to this within the family environment causes children to replicate such communications when engaging with their co-twin. Furthermore, children belonging to a positive family climate, within which they are likely to experience more positive comments and behavior from their mother, may feel more secure and settled in the home and such internal feelings may, in turn, be more conducive to a child playing nicely with their sibling(s) (Teti \& Ablard, 1989).

It is also possible that the observed spill-over between the maternal emotional climate and family-wide twin relationship quality can be explained by common genetic influences. In a previous study, conducted with a large Swedish sample of adult twins, Ganiban and colleagues (2007) revealed that heritable characteristics of parents can help shape the overall emotional climate of the family. Specifically, they found that parental genetic influences explained nearly half of the covariance between marital satisfaction and family-wide mothering and fathering. While this research did not directly test our variables of interest (maternal expressed emotion and sibling relationships), the mechanisms are relevant. Such findings suggest that genetically driven spill-over from parents occurs within the home environment; thus this possibility should be considered within the current study. Specifically, the link between mothers' positive expressed emotion and the way their twins get along may be mediated by mothers' genetically influenced perceptions and behaviors, and these same genetic propensities may be operating within the twin relationship via passive gene-environment correlations. It is worth noting, however, that when investigating the role of genes in maternal expressed emotion explicitly, Caspi and colleagues (2004) concluded that the measure is a predominantly environmental experience that accounts for children's behavior.

While considering the salience of parental genes, we must also touch upon the possibility that the affective tone of the twin relationship evokes similar emotional responses from the mother. An extended children-of-twins model, employing twin parents and their children, as well as twin children and their parents, can allow testing of the direction of the association between parenting and children's outcomes (Silberg \& Eaves, 2004). Indeed, one such study showed that evocative genotype-environment correlations could best explain spill-over within families (Narusyte et al., 2008). It is tempting to accept a mother-driven effect; yet, according to Narusyte and colleagues (2008), we would be wise to assume that the association between maternal expressed emotion and the sibling bond is bidirectional. That is, shared genes possessed by twins, such as those influencing positivity between the siblings, may induce more positive feelings from the mother toward the children. This more unusual interpretation is worth bearing in mind when considering the results presented here.

\section{Differential Mothering and Twin Relationship Quality}

Contrary to our hypothesis (c), and opposing McHale and colleagues' (1995) view that the sibling relationship tends to be negatively affected by unequal parental treatment, differential expressed emotion from mothers toward their children weakly predicted twin relationship quality positivity, over and above a questionnaire measure of the motherchild relationship. In other words, mothers who made proportionately more positive than critical comments about one twin in comparison to the other also reported more affection between their two twin children; whereas equal expressed emotion by mothers was linked to less twin sibling positivity.

While emphasizing child-specific mothering, these findings directly oppose the previous literature showing that discrepancies in parenting are negatively associated with brotherly and sisterly interactions (Dunn \& Munn, 1985). The lack of results for negative twin relationship quality is somewhat surprising, considering the belief that feelings of anger and rivalry tend to be induced in the less favored sibling in the face of parental differential treatment (Brody et al., 1992; Richmond et al., 2005). However, this does tie in with the compensatory hypothesis put forward by Hay and colleagues (1998). These authors found that the more hostile a mother's behavior toward one of her children compared to the other, the less the favored child objected to their brother or sister. Perhaps dealing with the demands of parental differential treatment leads siblings to rely on, or care for, each other, and thus increases affection between them. It is also worth noting here that while our measure of expressed emotion was very informative, the presence of mothers' differential feelings toward their twins is not necessarily an indicator of actual differential behavior.

\section{Generalizability}

This research employed families with young twin children in a bid to understand the link between mothering, and 
particularly maternal expressed emotion, and sibling relationship quality in these unusual fraternal dyads. By recruiting twin siblings, age and age gap variances are automatically controlled for, meaning a large determining factor of parenting is removed (O'Connor \& Croft, 2001). Eliminating these central confounding factors within the sibling dyads meant that we were able to capture a more nuanced outlook into family life. Ultimately, twins are a sharp scalpel for eradicating demographic inequalities from brother and sister pairs (Fraley \& Tancredy, 2012), allowing us to put aspects of parenting - family-wide and child-specific mothering here - under the microscope.

Twin relationships themselves have repeatedly been portrayed as exceptionally special and intimate (Burlington, 1945; Fraley \& Tancredy, 2012; Playfair, 2002; Segal, 1999). Moreover, parents are thought to encounter unique childrearing experiences when raising twins. For example, it is known that mothers tend to be less responsive to, to have less physical contact with, and to talk less to twins in comparison to non-twins (Leonard \& Denton, 2006). Indeed, Beck (2002) claims that parents' unique involvement in childrearing within this context often results in feelings of guilt and inadequacy. Interestingly, however, our pattern of results runs contrary to previous research, emphasizing the individuality of the twin bond, and instead bolsters our earlier work justifying the generalization of non-twin outcomes to samples of twins (Mark et al., 2016). In the current study, we found that maternal expressed emotion predicted the bond between twins, just as it predicts the bond between non-twin brothers and sisters (Petalas et al., 2012). Thus, this paper also demonstrates generalizability across twin and non-twin siblings. Saying this, such results are novel, and do require replication.

\section{Limitations and Future Directions}

An important limitation within our research comes from the fact that the quality of both the mother-child and the twin sibling bond was reported on by mothers, meaning that these constructs could have shared variance. This may have inflated the significance of the results found here. A future study would benefit from assessing the impact of maternal expressed emotion on twin relationship quality using children's perspectives alongside parental views. We know that parents tend to over-estimate the consistency of their behavior toward their offspring, and of their children's behavior toward them and other family members (Pike et al., 1996). Additionally, children's observations about the fairness of equal, or unequal, parental treatment toward siblings may be the most salient factor when assessing sibling relationship quality (Kowal \& Kramer, 1997).

It is also important to acknowledge that families in this study were not fully representative of the United Kingdom's population. First, we only focused on mothers within our sample, despite the fact that the majority of participating twin children belonged to a two-parent household. Brody and colleagues (1994) have shown the particular importance of fathers in forecasting sibling relationship quality, perhaps because their unavailability bestows a certain psychological salience on their relationships with their children, making dyadic characteristics more likely to spill over. Second, these mothers were well educated, and, as such, our sample was skewed toward the higher end of the socioeconomic spectrum. Numerous studies have found that demographics such as social class and race can affect family dynamics (Bronfenbrenner, 1992), so this must be borne in mind. Finally, we focused on children within a very specific age range in this sample, and we acknowledge that sibling relationships can vary in their nature over time. It may be that twins become more alike, and therefore closer, as they grow older, because they live apart and no longer have the need to establish distinct identities within the family home (Neyer, 2002). In order to extend the application of our findings then, future research exploring the links between expressed emotion and twin relationship quality should gain information from mothers and fathers of older twins, from more diverse socio-economic and ethnic backgrounds.

\section{Conclusions}

As expected from family systems theory (Bowen, 1978) and the spill-over hypothesis (Engfer, 1988), this research demonstrates that individual relationships within the family influence each other. It was found that mothers' family-wide expressed emotion toward their twin children predicted positive twin relationship quality more strongly than did differential expressed emotion. Therefore, the overall family climate, rather than child-specific experiences within the home, was most salient for determining positivity within the twin sibling dyad. Crucially, evidence for the usefulness of the Preschool Five Minute Speech Sample (Daley et al., 2003) is provided here. The prediction of twin relationship quality positivity from expressed emotion held after mothers' questionnaire reports of their relationship with their children had been taken into account, indicating that speech samples add a unique perspective. Consequently, assessing expressed emotion within the home environment is important for gaining a complete picture of twin family life.

\section{References}

Baker, B. L., Heller, T. L., \& Henker, B. (2000). Expressed emotion, parenting stress, and adjustment in mothers of young children with behavior problems. Journal of Child Psychology, 41, 907-915.

Bandura, A. (1977). Social learning theory. Englewood Cliffs, NJ: Prentice Hall.

Beck, C. T. (2002). Releasing the pause button: Mothering twins during the first year of life. Qualitative Health Research, 12, 593-608. 
Bowen, M. (1978). Family therapy in clinical practice. Northvale, NJ: Jason Aronson.

Brody, G. H. (1998). Sibling relationship quality: Its causes and consequences. Annual Review of Psychology, 49, 1-24.

Brody, G. H., Stoneman, Z., \& McCoy, J. K. (1994). Forecasting sibling relationships in early adolescence from child temperaments and family processes in middle childhood. Child Development, 65, 771-784.

Brody, G. H., Stoneman, Z., McCoy, J. K., \& Forehand, R. (1992). Contemporaneous and longitudinal associations of sibling conflict with family relationship assessments and family discussions about sibling problems. Child Development, 63, 391-400.

Brody, L. R., Copeland, A. P., Sutton, L. S., Richardson, D. R., \& Guyer, M. (1998). Mommy and daddy like you best: Perceived family favouritism in relation to affect, adjustment and family process. Journal of Family Therapy, 20, 269-291.

Bronfenbrenner, U. (1992). Ecological systems theory. In R. Vasta (Ed.), Six theories of child development: Revised formulations and current issues (pp. 187-249). London, England: Jessica Kingsley Publishers.

Brown, G. W., \& Rutter, M. L. (1966). The measurement of family activities and relationships. Human Relations, 19, 241-263.

Burlington, D. T. (1945). The fantasy of having a twin. In R. S. Eissler (Ed.), The psychoanalytic study of the child (pp. 205-210). London, UK: Yale University Press.

Cartwright, K. L., Bitsakou, P., Daley, D., Gramzow, R. H., Psychogiou, L., Simonoff, E., ... Sonuga-Barke, E. J. S. (2011). Disentangling child and family influences on maternal expressed emotion toward children with attention-deficit/hyperactivity disorder. Journal of the American Academy of Child and Adolescent Psychiatry, 50, 1042-1053.

Caspi, A., Moffitt, T. E., Morgan, J., Rutter, M., Taylor, A., Arseneault, L., ... Polo-Tomas, M. (2004). Maternal expressed emotion predicts children's antisocial behavior problems: Using monozygotic-twin differences to identify environmental effects on behavioral development. Developmental Psychology, 40, 149-161.

Daley, D., Sonuga-Barke, E. J. S., \& Thompson, M. (2003). Assessing expressed emotion in mothers of preschool $\mathrm{AD} / \mathrm{HD}$ children: Psychometric properties of a modified speech sample. British Journal of Clinical Psychology, 42, 53-67.

Dunn, J., \& Munn, P. (1985). Becoming a family member: Family conflict and the development of social understanding in the second year. Family Development and the Child, 56, 480-492.

Dunn, J., Stocker, C., \& Plomin, R. (1990). Nonshared experiences within the family: Correlates of behavioral problems in middle childhood. Development and Psychopathology, 2, 113-126.

Engfer, A. (1988). The interrelatedness of marriage and the mother-child relationship. In R. A. Hinde \& J. StevensonHinde (Eds.), Relationships within families: Mutual influences (pp. 104-118). New York, NY: Oxford University Press.
Erel, O., \& Burman, B. (1995). Interrelatedness of marital relations and parent-child relations: A meta-analytic review. Psychological Bulletin, 118, 108-132.

Fraley, R. C., \& Tancredy, C. M. (2012). Twin and sibling attachment in a nationally representative sample. Personality and Social Psychology Bulletin, 38, 308-316.

Ganiban, J. M., Spotts, E. L., Lichtenstein, P., Khera, G. S., Reiss, D., \& Neiderhiser, J. M. (2007). Can genetic factors explain the spillover of warmth and negativity across family relationships?. Twin Research and Human Genetics, 10, 299-313.

Hay, D. F., Vespo, J. E., \& Zahn-Waxler, C. (1998). Young children's quarrels with their siblings and mothers: Links with maternal depression and bipolar illness. British Journal of Developmental Psychology, 16, 519-538.

Hetherington, E. M., \& Clingempeel, W. G. (1992). Coping with marital transitions: A family systems perspective. Monographs of the Society for Research in Child Development, 57, 1-242.

Jenkins, J., Rasbash, J., Leckie, G., Gass, K., \& Dunn, J. (2012). The role of maternal factors in sibling relationship quality: A multilevel study of multiple dyads per family. Journal of Child Psychology and Psychiatry, 53, 622629.

Kowal, A. K., Krull, J. L., \& Kramer, L. (2006). Shared understanding of parental differential treatment in families. Social Development, 15, 276-295.

Kowal, A., \& Kramer, L. (1997). Children's understanding of parental differential treatment. Child Development, 68, 113126.

Leff, J., \& Vaughn, C. (1981). The role of maintenance therapy and relatives' expressed emotion in relapse of schizophrenia. The British Journal of Psychiatry, 139, 102-104.

Leonard, L. G., \& Denton, J. (2006). Preparation for parenting multiple birth children. Early Human Development, 82, 371-378.

Magana, A. B., Goldstein, M. J., Karno, M., Miklowitz, D. J., Jenkins, J., \& Falloon, I. R. H. (1986). A brief method for assessing expressed emotion in relatives of psychiatric patients. Psychiatry Research, 17, 203-212.

Mark, K. M., Pike, A., Latham, R. M., \& Oliver, B. R. (2016). Using twins to better understand sibling relationships. Behavior Genetics.

McCarthy, C. A., Lau, A. S., Valeri, S. M., \& Weisz, J. R. (2004). Parent-child interactions in relation to critical and emotionally over involved expressed emotion (EE): Is EE a proxy for behavior?. Journal of Abnormal Child Psychology, 32, 83-93.

McHale, S. M., Crouter, A. C., McGuire, S. A., \& Updegraff, K. A. (1995). Congruence between mothers' and fathers' differential treatment of siblings: Links with family relations and children's well-being. Child Development, 66, $116-128$

Narusyte, J., Neiderhiser, J. M., D’Onofrio, B. M., Reiss, D., Spotts, E. L., Ganiban, J., \& Lichtenstein, P. (2008). Testing different types of genotype-environment correlation: An extended children-of-twins model. Developmental Psychology, 44, 1591-1603. 
Neyer, F. J. (2002). Twin relationships in old age: A developmental perspective. Journal of Social and Personal Relationships, 19, 155-177.

O'Connor, T. G., \& Croft, C. M. (2001). A twin study of attachment in preschool children. Child Development, 72, 15011511.

Office for National Statistics. (2013). Births in England and Wales by characteristics of birth 2, 2013. London, England: Office for National Statistics.

Office for National Statistics. (2014). Local area analysis of qualifications across England and Wales. London, England: Office for National Statistics.

Petalas, M. A., Hastings, R. P., Nash, S., Hall, L. M., Joannidi, H., \& Dowey, A. (2012). Psychological adjustment and sibling relationships in siblings of children with autism spectrum disorders: Environmental stressors and the broad autism phenotype. Research in Autism Spectrum Disorders, 6, 546-555.

Pike, A., Coldwell, J., \& Dunn, J. F. (2005). Sibling relationships in early/middle childhood: Links with individual adjustment. Journal of Family Psychology, 19, 523-532.

Pike, A., \& Oliver, B. R. (2015). Parenting in childhood. In B. N. Horwitz \& J. M. Neiderhiser (Eds.), Gene-environment interplay in interpersonal relationships across the lifespan (pp. 57-81). New York, NY: Spring Science and Business Media.

Pike, A., Reiss, D., Hetherington, E. M., \& Plomin, R. (1996). Using MZ differences in the search for nonshared environmental effects. Journal of Child Psychology and Psychiatry, 37, 695-704.

Playfair, G. L. (2002). Twin telepathy: The psychic connection. London, England: Vega.

Plomin, R., Rende, R., \& Rutter, M. (1991). Quantiative genetics and developmental psychopathology. In D. Cicchetti, \& S. Toth (Eds.), Rochester symposium on developmental psychopathology: Internalising and externalising expressions of dysfunction: Vol. 2 (pp. 155-202). Hillsdale, NJ: Lawrence Erlbaum Associates.
Price, T. S., Freeman, B., Craig, I., Petrill, S. A., Ebersole, L., \& Plomin, R. (2000). Infant zygosity can be assigned by parental report questionnaire data. Twin Research, 3, 129133.

Richmond, M. K., Stocker, C. M., \& Rienks, S. L. (2005). Longitudinal associations between sibling relationship quality, parental differential treatment, and children's adjustment. Journal of Family Psychology, 19, 550-559.

Segal, N. L. (1999). Entwined lives: Twins and what they tell us about human behaviour. New York, NY: Penugin Books.

Shanahan, L., McHale, S. M., Crouter, A. C., \& Osgood, D. W. (2008). Linkages between parents' differential treatment, youth depressive symptoms, and sibling relationships. Journal of Marriage and Family, 70, 480-494.

Silberg, J. L., \& Eaves, L. J. (2004). Analysing the contributions of genes and parent-child interaction to childhood behavioural and emotional problems: A model for the children of twins. Psychological Medicine, 34, 347356.

Stocker, C., Dunn, J., \& Plomin, R. (1989). Sibling relationships: Links with child temperament, maternal behavior, and family structure. Child Development, 60, 715727.

Straus, M. A., Gelles, R. J., \& Steinmetz, S. K. (Eds.). (1980). Behind closed doors: Violence in the American family. New York, NY: Transaction Publishers.

Teti, D. M., \& Ablard, K. E. (1989). Security of attachment and infant-sibling relationships: A laboratory study. Child Development, 60, 1519-1528.

Wamboldt, F. S., O’Connor, S. L., Wamboldt, M. Z., Gavin, L. A., \& Klinnert, M. D. (2000). Journal of Child Psychology and Psychiatry, 41, 887-898.

Whiteman, S. D., McHale, S. M., \& Soli, A. (2011). Theoretical perspectives on sibling relationships. Journal of Family Theory and Review, 3, 124-139.

Yelland, I., \& Daley, D. (2009). Expressed emotion in children: Associations with sibling relationships. Child: Care, Health and Development, 35, 568-577. 